\title{
RESEARCH
}

Open Access

\section{Selected features of breast and peritoneal cancers diagnosed in BRCA1 carriers after risk-reducing salpingo-oophorectomy}

Janusz Menkiszak', Anita Chudecka-Głaz', Aneta Cymbaluk-Płoska' ${ }^{1}$, Aleksander Celewicz' ${ }^{1}$, Zbigniew Kojs², Mariusz Szajda ${ }^{3}$, Maria Świniarska ${ }^{4}$, Ryszard Bedner $^{1}$, Anna Jurczak ${ }^{5}$, Marta Celewicz ${ }^{6}$, Monika Cieszyńska Jan Lubiński ${ }^{3}$ and Jacek Gronwald ${ }^{3^{*}}$

\begin{abstract}
Background: Since more than two decades Risk-reducing salpingo-oophorectomy (RRSO) is recommended and widely accepted by BRCA1/2 carriers as a method reducing ovarian cancer risk and improving survival rate. After RRSO, there remains a risk of breast cancer and peritoneal cancer. The characteristics of these neoplasms are not well known. In this study, we determined the selected parameters such as age at cancer diagnosis, time from RRSO to the diagnosis of cancer, and significance of BRCA1 mutation type in patients diagnosed with breast or peritoneal cancer during postoperative follow-up.

Methods: The material comprised of 195 BRCA1 carriers who performed RRSO between years 1999-2012. In this period, 16 patients developed cancer (6-primary breast cancer, 3-contralateral breast cancer, 5-relapse of breast cancer, 2-peritoneal cancer). They were subject of the further analysis.

Results: During the follow-up period mean age of patients after RRSO at the time of cancer diagnosis was 53.19. The mean age of patients diagnosed with primary breast cancer was 50, contralateral breast cancer - 58.67, recurrence of breast cancer - 51 and peritoneal cancer 60 . The mean time periods from RRSO to the diagnosis of primary, contralateral, recurrence breast cancer were 53,58.67 and 25,4 months respectively and of peritoneal cancer 46 months. BRCA1 c.5266dupC mutation carriers demonstrated significantly shorter time of cancer development compared to patients carrying c.181T > G and c.4035delA mutations. Peritoneal cancer was only observed in two c.181T > G BRCA1 mutation carriers.
\end{abstract}

Conclusions: The mean age of cancer diagnosis and the mean time periods from RRSO to the diagnosis of cancer are similar to those observed by other researchers. The carriers of c.181T $>\mathrm{G}$ and c.5266dupC BRCA1 mutation should be the subject further studies in context of breast and peritoneal cancer risk or time of cancer development after RRSO, respectively.

Keywords: BRCA1 mutation, Cancer, Prophylactic surgery

\footnotetext{
* Correspondence: jgron@pum.edu.pl

${ }^{3}$ International Hereditary Cancer Center, Department of Genetics and

Pathology, Pomeranian Medical University, Szczecin, Poland

Full list of author information is available at the end of the article
}

(c) The Author(s). 2019 Open Access This article is distributed under the terms of the Creative Commons Attribution 4.0 International License (http://creativecommons.org/licenses/by/4.0/), which permits unrestricted use, distribution, and reproduction in any medium, provided you give appropriate credit to the original author(s) and the source, provide a link to the Creative Commons license, and indicate if changes were made. The Creative Commons Public Domain Dedication waiver (http://creativecommons.org/publicdomain/zero/1.0/) applies to the data made available in this article, unless otherwise stated. 


\section{Introduction}

It was shown that diagnostic methods for ovarian cancer early-stage detection are ineffective [1]. Intensive screening tests in groups with the highest risk of ovarian cancer, such as carriers of the BRCA1 and BRCA2 mutations, have also low efficacy [1-6]. For these reasons, patients who are carriers of the $B R C A 1 / 2$ mutation are offered risk-reducing salpingo-oophorectomies (RRSO), which is widely accepted by $B R C A 1 / 2$ carriers and have been performed for decades in hospitals and gynecological clinics all around the world. At the moment, such management is considered the best possible option for reducing ovarian cancer risk and improving the survival rate $[1,7,8]$. However, after this surgery, there remains a risk of breast cancer and risk of peritoneal cancer. Data about characteristics of these cancers developing after RRSO are pure. In this study, we analyzed characteristics of breast or peritoneal cancer after RRSO. Follow-up was conducted over the course of 12 years. The analysis included: age at cancer diagnosis, time from RRSO to the diagnosis of cancer, significance of $B R C A 1$ mutation type in patients diagnosed with breast or peritoneal cancer during postoperative follow-up.

\section{Material and methods}

The material comprised of 195 BRCA1 carriers from the West Pomeranian Voivodship in Poland who performed RRSO between 15.09.1999-31.12.2012 at the Department of Gynecological Surgery and Oncology of Adults and Adolescents of the Pomeranian Medical University in Szczecin. No malignancy was found in the histopathological examination of the excised material. 80 of 195 (41.03\%) patients were treated for breast cancer before risk-reducing surgery. All patients carried one of three BRCA1 mutations most commonly occurring in the Polish population (c.5266dupC - 128 patients, c. 4035 delA - 19 patients and c. 181 T > G - 48 patients) [9]. Median follow-up time for the group of 195 patients amounted to 80 months.

At the time of observation 16 out of 195 patients were diagnosed with cancer. 6 (3.1\%) cases with primary breast cancer (PBC); 3 (1.5\%) cases contralateral primary breast cancer (CPBC); 5 (2.56\%) cases with cancer cells diagnosed in a scar after mastectomy defined as relapse of breast cancer (RBC); 2 (1.03\%) cases with peritoneal cancer. The detailed characteristics of 16 patients from the study group are shown in Table 1 . Ten (62.5\%) of these patients had been treated for breast cancer also before the RRSO. The median age of affected patients $(n=16)$ at the time of RRSO was 46.5 years (36-63 years), which did not deviate from median age for the whole group $(n=195)-47$ years $(31-78$ years $)$.

Histopathological examination of tissues excised during RRSO was performed with extraordinary caution in order to rule out the presence of cancerous foci in the ovary or the salpinx, which have been described in the literature and could have been missed in the primary histopathological assessment [10, 11]. Repeated histopathological examination of excised material failed to reveal micro-invasive foci in both of our patients diagnosed with primary peritoneal cancer during the follow-up period.

The patient analysis included: age at cancer diagnosis, time from RRSO to the diagnosis of cancer, significance of BRCA1 mutation type in patients diagnosed with breast or peritoneal cancer during postoperative follow-up. The data has been subjected to statistical analysis.

\section{Statistical analysis}

All variables were checked for normal distribution using the Shapiro-Wilk test. They were described as means, standard deviations, medians, quartiles, as well as minimal and maximal values. We checked for statistically significant differences in quantitative variables using Student's t-test or Mann-Whitney test and Fisher's exact test were used in order to calculate differences in proportions. For all tests, the differences were considered statistically significant at $p$-value $<0.05$. Statistical analyses were performed using STATA 11 software (license no. 30110532736).

\section{Results}

Summary of selected features of BRCA1 carriers diagnosed with cancer during the follow-up period is shown in Table 2. The mean age of cancer diagnosis in 16 patients who were subject of the study, was 53.19. Peritoneal cancer observed in two patients was diagnosed significantly later at a mean age of 60 . Both patients were previously treated (before RRSO) due to breast cancer. With regards to breast cancer, the $\mathrm{PBC}$ was diagnosed in $6, \mathrm{CPBC}$ in 3 and $\mathrm{RBC}$ in 5 out of 16 cases. The peritoneal cancer was diagnosed almost 7 months earlier than PBC (46 months vs. 53 months), but this difference was not statistically significant. Breast cancer recurrence was diagnosed almost twice as fast as primary breast cancer and peritoneal cancer (25.4 vs. 53 months), but this difference was also not statistically significant.

Peritoneal cancers diagnosed during the follow-up period were observed only in two c.181T > G BRCA1 mutation carriers. We performed a statistical analysis of the frequency of peritoneal cancer in c.181T > G BRCA1 mutation carriers in comparison to other mutation carriers. Statistical significant differences were observed for this characteristic $(p=0.0392 ; \mathrm{OR}=29.00 ; 95 \% \mathrm{CI}$ : 1.048-802.64). 
Table 1 Characteristics of 16 patients who developed cancer after risk-reducing salpingo-oophorectomy

\begin{tabular}{|c|c|c|c|c|c|c|}
\hline $\begin{array}{l}\text { Patient } \\
\text { number }\end{array}$ & $\begin{array}{l}\text { BRCA1 mutation } \\
\text { type }\end{array}$ & $\begin{array}{l}\text { Cancer diagnosed before } \\
\text { prophylactic surgery } \\
\text { (yes/no) location }\end{array}$ & $\begin{array}{l}\text { Date of prophylactic } \\
\text { surgery (month/year) }\end{array}$ & $\begin{array}{l}\text { Date of cancer diagnosis } \\
\text { after prophylactic } \\
\text { surgery (month/year) }\end{array}$ & $\begin{array}{l}\text { Cancer diagnosed } \\
\text { after prophylactic } \\
\text { surgery (location) }\end{array}$ & $\begin{array}{l}\text { Time from risk-reducing } \\
\text { surgery to cancer } \\
\text { diagnosis (months) }\end{array}$ \\
\hline 1. & c.5266dupC & Yes breast & $02 / 2008$ & 06/2008 & $\begin{array}{l}\text { breast - second } \\
\text { primary }\end{array}$ & 4 \\
\hline 2. & c.5266dupC & Yes breast & 06/2006 & $04 / 2008$ & $\begin{array}{l}\text { breast } \\
\text {-recurrence }\end{array}$ & 22 \\
\hline 3. & c. $181 T>$ G & Yes breast & 09/1999 & $11 / 2004$ & peritoneum & 62 \\
\hline 4. & c.5266dupC & Yes breast & $11 / 2002$ & 05/2004 & $\begin{array}{l}\text { breast } \\
\text {-recurrence }\end{array}$ & 18 \\
\hline 5. & c.181T > G & Yes breast & $02 / 2001$ & 08/2003 & peritoneum & 30 \\
\hline 6. & c.5266dupC & Yes breast & $01 / 2002$ & $04 / 2008$ & $\begin{array}{l}\text { breast } \\
\text {-recurrence }\end{array}$ & 75 \\
\hline 7. & c.181T > G & no & 08/2003 & 06/2008 & breast - primary & 58 \\
\hline 8. & c.5266dupC & no & $06 / 2002$ & $10 / 2006$ & breast - primary & 52 \\
\hline 9. & c.5266dupC & Yes breast & 09/2001 & $01 / 2002$ & $\begin{array}{l}\text { breast } \\
\text {-recurrence }\end{array}$ & 4 \\
\hline 10. & c.5266dupC & no & $11 / 2001$ & $01 / 2008$ & breast - primary & 74 \\
\hline 11. & c.5266dupC & no & $04 / 2006$ & 03/2008 & breast - primary & 23 \\
\hline 12. & c.5266dupC & Yes breast & $06 / 2004$ & $06 / 2006$ & $\begin{array}{l}\text { breast - second } \\
\text { primary }\end{array}$ & 24 \\
\hline 13. & c.4035delA & no & $11 / 2002$ & 07/2009 & breast primary & 80 \\
\hline 14. & c. $181 \mathrm{~T}>\mathrm{G}$ & Yes breast & $05 / 2000$ & $09 / 2012$ & $\begin{array}{l}\text { breast - second } \\
\text { primary }\end{array}$ & 148 \\
\hline 15. & c.5266dupC & Yes breast & $07 / 2002$ & $03 / 2003$ & $\begin{array}{l}\text { breast } \\
\text {-recurrence }\end{array}$ & 8 \\
\hline 16. & c.5266dupC & no & $11 / 2000$ & 06/2003 & breast - primary & 31 \\
\hline
\end{tabular}

The time to any cancer diagnosis after RRSO was significantly shorter for c.5266dupC mutation carriers compared to c. $181 \mathrm{~T}>\mathrm{G}$ and c.4035delA mutation carriers (30.45 vs. 75.6 months; $p=0.021$ ).

The c.5266dupC BRCA1 mutation was most frequent among patients who developed any cancer - 68.75\% $(11 / 16)$, followed by c. $181 \mathrm{~T}>\mathrm{G}$ mutation $-25 \%(4 / 16)$, and c.4035delA observed in 6,25\% (1/16) of patients. This reflects the frequency of these mutations in the Polish population.

\section{Discussion}

In our material, we observed relatively advanced age of cancer diagnosis among BRCA1 carriers after RRSO. It is most likely associated with particularly late age of undergoing this surgery. In our study, the average age of undergoing such an operation is 46-49 years [12-14]. The reason for delayed RRSO was that, in a significant number of breast cancer patients, $B R C A 1$ mutation was diagnosed after diagnosis of breast cancer. In our study group, $62.5 \%$ of patients had been previously treated due

Table 2 Summary of selected features of BRCA1 carriers diagnosed with cancer during the follow-up period

\begin{tabular}{|c|c|c|c|c|c|}
\hline $\begin{array}{l}\text { Type and number } \\
\text { Feature and type of mutation }\end{array}$ & $\begin{array}{l}\text { Peritoneal } \\
\text { cancer } \\
n=2\end{array}$ & $\begin{array}{l}\text { Primary } \\
\text { breast cancer } \\
n=6\end{array}$ & $\begin{array}{l}\text { Contralateral } \\
\text { breast cancer } \\
n=3\end{array}$ & $\begin{array}{l}\text { Breast cancer } \\
\text { recurrence } \\
n=5\end{array}$ & $\begin{array}{l}\text { Total for the whole } \\
\text { group diagnosed } \\
\text { with cancers } \\
n=16\end{array}$ \\
\hline $\begin{array}{l}\text { Patient age at the time of cancer diagnosis } \\
\text { (mean; years old) }\end{array}$ & 60 & 50.00 & 58.67 & 51.00 & 53.19 \\
\hline $\begin{array}{l}\text { Time from RRSO to cancer diagnosis } \\
\text { (mean; months) }\end{array}$ & 46 & 53 & 58.67 & 25.4 & 44,56 \\
\hline $\begin{array}{l}\text { Type of BRCA1 mutation in patients who developed } \\
\text { cancer during follow-up period }\end{array}$ & $2 \times c .181 T>G$ & $\begin{array}{l}4 \times \text { c.5266dupC } \\
1 \times \text { c.181T>G } \\
1 \times \text { c.4035delA }\end{array}$ & $\begin{array}{l}2 \times \text { c. } 5266 \text { dupC } \\
1 \times \text { c. } 181 T>G\end{array}$ & $5 \times$ c.5266dupc & $\begin{array}{l}11 \times c .5266 \mathrm{dupC} \\
4 \times c .181 \mathrm{~T}>\mathrm{G} \\
1 \times \text { c. } 4035 \text { delA }\end{array}$ \\
\hline
\end{tabular}


to breast cancer. As indicated in our previous studies, patients treated for breast cancer undergo RRSO at a later age compared to patients without the diagnosis of breast cancer (50 vs. 46 years; $p=0.0003$ ) [13].

In our study, we found that the mean age at diagnosis of any breast cancer was similar to those observed by Ramon et al. and equaled 52.2 vs. 51.8 years of age. The mean time from RRSO to diagnosis of breast cancer was also similar and amounted to 44,35 vs. 40.8 months [15]. Fakkert et al. reported breast cancer diagnosis among $B R C A 1$ patients after RRSO at a significantly younger age - 45.25 years, and somewhat longer time from RRSO to the diagnosis of breast cancer - 52.8 months [16]. Kauff et al. indicated significantly shorter time to diagnosis of breast and peritoneal cancer among patients after RRSO - 10.3 and 16.3 months, respectively [17].

Finch et al. showed that mean time to development of peritoneal cancer among BRCA1 carriers after RRSO amounted to 63.6 months, although they emphasize that in three cases the diagnosis was made before the end of three years. The mean age of those patients at the time of diagnosis equalled 51.5 years [18], which approximates our data. In another study, Finch et al. reported similar mean age at diagnosis of peritoneal cancer -51.6 years, but the mean time to diagnosis extended to 73.2 months. Possibly, prolonged time to the diagnosis of peritoneal cancer might have been influenced by the inclusion of four patients with $B R C A 2$ mutation into the study group of 32 patients [19]. In case of particularly short time to diagnosis of peritoneal cancer after RRSO, one should very carefully assess the excised material in order to rule out micro-invasive foci, which is described in the literature $[10,11]$.

Rhiem et al. observed a case of peritoneal cancer in a 57-year-old woman 26.4 months after RRSO [20]. Rebbeck et al. diagnosed peritoneal cancer in patients 45.6 and 103.2 months after RRSO [21]. Kiely et al. showed peritoneal cancer in a 70-year-old patient eight 96 months after RRSO [22]. In another publication, Kauff et al. reported peritoneal cancers among patients after RRSO on average after 41.16 months and breast cancers after 36.36 months [23]. Powell et al. demonstrated equally short time of diagnosis of peritoneal cancer in a patient after RRSO as Kauff [17]. The diagnosis was made as early as a year after the procedure [24]. In our material, the mean age of patients diagnosed with peritoneal cancer was 60 and the mean time from RRSO to the diagnosis of peritoneal cancer amounted to 46 months.

Influence of particular BRCA1 gene mutation on studied characteristics is a very difficult topic to discuss. Although c.5266dupC, the most common mutation in the Polish population, is also often identified in the Ashkenazi Jewish population [25], available literature lacks data for discussion. The frequency of particular $B R C A 1$ mutations observed between carriers who were diagnosed with any cancer reflects the frequency of these mutations in the Polish population. However, we found peritoneal cancer in two BRCA1 carriers with c.181T > $\mathrm{G}$ mutation, only. These two patients also developed breast cancer before RRSO. We observed that the time to any cancer diagnosis after RRSO was significantly shorter for c.5266dupC BRCA1 mutation carriers. We think that these are interesting observations important for future analyses on significance of particular BRCA1 gene mutation, however, for more general conclusions studies on larger groups should be performed.

\section{Conclusions}

The mean age of cancer diagnosis and the mean time periods from RRSO to the diagnosis of cancer are similar to those observed by other researchers. The carriers of c.181T > G and c.5266dupC BRCA1 mutation should be the subject further studies in context of breast and peritoneal cancer risk or time of cancer development after RRSO, respectively.

\section{Abbreviations \\ Cl: Confidence interval; CPBC: Contralateral primary breast cancer; OR: Odds ratio; PBC: Primary breast cancer; RBC: Relapse of breast cancer; RRSO: Risk- reducing salpingo-oophorectomy}

\section{Acknowledgements \\ Authors thank for support to Breast Cancer Campaign Estée Lauder Companies.}

\section{Funding}

Not applicable.

\section{Availability of data and materials}

The datasets used and/or analyzed during the current study are available from the corresponding author on reasonable request.

\section{Authors' contributions}

JM the study design, database management, data collection and computing results, writing manuscript; AC-G sample collection, the manuscript review and approval; AC-P data collection, the manuscript review and approval; AC data collection, data collection and computing results, writing manuscript; ZK the study design, the manuscript review and approval; MS computing results, the manuscript review and approval, MŚ sample collection, the manuscript review and approval; RB sample collection, the manuscript review and approval; AJ sample collection, the manuscript review and approval; MC sample collection, the manuscript review and approval; MC sample collection, the manuscript review and approval; $J$ the study design, the manuscript review and approval; JG: the study design, database management, sample collection and computing results, molecular analysis, writing manuscript. All authors read and approved the final manuscript.

Ethics approval and consent to participate

All participants gave informed written consent prior blood donating. The study was approved by Ethics Committee of the Pomeranian Medical University in Szczecin, Poland (decision No. BN-001/174/05).

Consent for publication

Not applicable.

Competing interests

The authors declare that they have no competing interests. 


\section{Publisher's Note}

Springer Nature remains neutral with regard to jurisdictional claims in published maps and institutional affiliations.

\section{Author details \\ 'Department of Gynecological Surgery and Gynecological Oncology of Adults and Adolescents, Pomeranian Medical University, Szczecin, Poland. ${ }^{2}$ Department of Gynecologic Oncology, Centre of Oncology, Maria Sklodowska-Curie Memorial Institute, Branch, Cracow, Poland. International Hereditary Cancer Center, Department of Genetics and Pathology, Pomeranian Medical University, Szczecin, Poland. ${ }^{4}$ Department of the Clinical Oncology the West Pomeranian Centre of the Oncology in Szczecin, Szczecin, Poland. ${ }^{5}$ Department of Clinical Nursing, Pomeranian Medical University, Szczecin, Poland. ${ }^{6}$ Department of Obstetrics and Gynecology, Pomeranian Medical University, Szczecin, Poland.}

\section{Received: 28 January 2019 Accepted: 5 March 2019}

Published online: 14 March 2019

\section{References}

1. Walker JL, Bethan Powell C, Chen L-M, Carter J, Bae Jump VL, et al. Society of Gynecologic Oncology Recommendations for the prevention of ovarian Cancer. Cancer. 2015;121:2108-20.

2. Goff BA, Lowe KA, Kane JC, Robertson MD, Gaul MA, Andersen MR. Symptom triggered screening for ovarian cancer: a pilot study of feasibility and acceptability. Gynecol Oncol. 2012;24:230-5.

3. Goff BA. Ovarian cancer: screening and early detection. Obstet Gynecol Clin N Am. 2012;39:183-94.

4. Goff BA, Matthews B, Andrilla CH, Miller JW, Trivers KF, Berry D, et al. How are symptoms of ovarian cancer managed? A study of primary care physicians. Cancer. 2011;117:4414-23.

5. Goff B. Symptoms associated with ovarian cancer. Clin Obstet Gynecol. 2012:55:36-42

6. Buys SS, Partridge E, Black A, Johnson CC, Lamerato L, Isaacs C, et al. Effect of screening on ovarian cancer mortality: the prostate, lung, colorectal and ovarian (PLCO) cancer screening randomized controlled trial. JAMA. 2011;305:2295-303.

7. Gilbert L, Basso O, Sampalis J, Karp I, Martins C, Feng J, et al. Assessment of symptomatic women for early diagnosis of ovarian cancer: results from the prospective DOvE pilot project. Lancet Oncol. 2012;13:285-91.

8. Synowiec A, Wcisło G, Bodnar L, Gasowska-Bodnar A, Szczylik C. Screening for ovarian cancer in BRCA1/BRCA2 mutations carriers. Ginekol Pol. 2014;85(5):377-81.

9. Górski B, Byrski T, Huzarski T, Jakubowska A, Menkiszak J, Gronwald J, et al. Founder mutations in the BRCA1 gene in polish families with breast-ovarian cancer. Am J Hum Genet. 2000;66(6):1963-8.

10. Rabban JT, Krasik E, Chen LM, Powell CB, Crawford B, Zaloudek CJ. Multistep level sections to detect occult fallopian tube carcinoma in risk-reducing salpingo-oophorectomies from women with BRCA mutations: implications for defining an optimal specimen dissection protocol. Am J Surg Pathol. 2009:33:1878-85.

11. Reitsma W, de Bock GH, Oosterwijk JC, Bart J, Hollema H, Mourits MJ. Support of the 'fallopian tube hypothesis' in a prospective series of risk-reducing salpingo-oophorectomy specimens. Eur J Cancer. 2013;49:132-41.

12. Menkiszak J, Chudecka-Głaz A, Bedner R, Gronwald J, Wężowska M, Kojs Z, et al. Genital malignant tumors and precancerous conditions in female carriers of constitutional BRCA 1 gene mutations undergoing prophylactic adnexectomy. Curr Gynecol Oncol. 2012;10(4):270-85.

13. Menkiszak J, Chudecka-Głaz A, Gronwald J, Bedner R, Cymbaluk-Płoska A Wezżowska $\mathrm{M}$, et al. Characteristics of selected clinical features in BRCA1 mutation carriers affected with breast cancer undergoing preventive female genital tract surgeries. Ginekol Pol. 2013;84(9):758-64.

14. Menkiszak J, Chudecka-Głaz A, Gronwald J, Cymbaluk-Płoska A, Celewicz A, Świniarska M, et al. Prophylactic salpingo-oophorectomy in BRCA1 mutation carriers and postoperative incidence of peritoneal and breast cancers. J Ovarian Res. 2016 Feb;29(9):11. https://doi.org/10.1186/s13048-016-0220-4.

15. Ramon Y, Cajal T, Torres A, Alonso C, Fisas D, Ojeda B, et al. Risk factors associated with the occurrence of breast cancer after bilateral salpingooophorectomy in high-risk women. Cancer Epidemiol. 2011 Feb;35(1):78-82.
16. Fakkert IE, Mourits MJ, Jansen L, van der Kolk DM, Meijer K, Oosterwijk JC, et al. Breast Cancer incidence after risk-reducing Salpingo-oophorectomy in BRCA1 and BRCA2 mutation carriers. Cancer Prev Res (Phila). 2012;5(11):1291-7.

17. Kauff ND, Satagopan JM, Robson ME, Scheuer L, Hensley M, Hudis CA, et al. Risk-reducing salpingo-oophorectomy in women with a BRCA1 or BRCA2 mutation. N Engl J Med. 2002;346(21):1609-15.

18. Finch A, Beiner M, Lubinski J, Lynch HT, Moller P, Rosen B, et al. Salpingooophorectomy and the risk of ovarian, fallopian tube, and peritoneal cancers in women with a BRCA1 or BRCA2 mutation. JAMA. 2006:296(2):185-92.

19. Finch AP, Lubinski J, Møller P, Singer CF, Karlan B, Senter L, et al. Impact of oophorectomy on cancer incidence and mortality in women with a BRCA1 or BRCA2 mutation. J Clin Oncol. 2014;32(15):1547-53.

20. Rhiem K, Foth $D$, Wappenschmidt B, Gevensleben $H$, Büttner $R$, Ulrich $U$, et al. Risk-reducing salpingo-oophorectomy in BRCA1 and BRCA2 mutation carriers. Arch Gynecol Obstet. 2011;283(3):623-7.

21. Rebbeck TR, Lynch HT, Neuhausen SL, Narod SA, Van't Veer L, Garber JE, et al. Prevention and observation of surgical end points study group. Prophylactic oophorectomy in carriers of BRCA1 or BRCA2 mutations. N Engl J Med. 2002;346(21):1616-22.

22. Kiely BE, Friedlander ML, Milne RL, Stanhope L, Russell P, Jenkins MA, et al. Adequacy of risk-reducing gynaecologic surgery in BRCA1 or BRCA2 mutation carriers and other women at high risk of pelvic serous cancer. Familial Cancer. 2011;10(3):505-14.

23. Kauff ND, Domchek SM, Friebel TM, Robson ME, Lee J, Garber JE, et al. Riskreducing salpingo-oophorectomy for the prevention of BRCA1- and BRCA2associated breast and gynecologic cancer: a multicenter, prospective study. J Clin Oncol. 2008;26(8):1331-7.

24. Powell CB, Chen LM, McLennan J, Crawford B, Zaloudek C, Rabban JT, et al. Risk-reducing salpingo-oophorectomy (RRSO) in BRCA mutation carriers: experience with a consecutive series of 111 patients using a standardized surgical-pathological protocol. Int J Gynecol Cancer. 2011;21(5):846-51.

25. Satagopan JM, Boyd J, Kauff ND, Robson M, Scheuer L, Narod S, et al. Ovarian cancer risk in Ashkenazi Jewish carriers of BRCA1 and BRCA2 mutations. Clin Cancer Res. 2002;8(12):3776-81.

\section{Ready to submit your research? Choose BMC and benefit from:}

- fast, convenient online submission

- thorough peer review by experienced researchers in your field

- rapid publication on acceptance

- support for research data, including large and complex data types

- gold Open Access which fosters wider collaboration and increased citations

- maximum visibility for your research: over $100 \mathrm{M}$ website views per year

At BMC, research is always in progress.

Learn more biomedcentral.com/submissions 